\title{
MicroRNA-511 inhibits malignant behaviors of breast cancer by directly targeting SOX9 and regulating the PI3K/Akt pathway
}

\author{
YUYING ZHAO, WEIFENG PANG, NING YANG, LING HAO and LEI WANG \\ Department of Medical Oncology, The Fourth Affiliated Hospital of Harbin Medical University, \\ Harbin, Heilongjiang 150001, P.R. China
}

Received July 20, 2018; Accepted September 14, 2018

DOI: 10.3892/ijo.2018.4576

\begin{abstract}
Numerous studies have revealed that a subset of microRNAs (miRNAs) is aberrantly expressed in breast cancer. The dysregulation of miRNAs is involved in the tumorigenesis and progression of breast cancer due to their negative regulation of downstream target genes. Therefore, the identification of deregulated miRNAs in breast cancer may provide important insights into the diagnosis and treatment of patients with this disease. miRNA-511 (miR-511) has been identified to be deregulated in diverse human cancer types; however, neither the expression status nor the detailed roles of miR-511 in breast cancer have been clarified. Thus, it was aimed to determine the expression of miR-511 in breast cancer, examine the role in malignant progression and explore its downstream targets. The results of the present study revealed that the expression of miR-511 was downregulated in breast cancer tissues and cell lines. Decreased expression of miR-511 was significantly associated with lymph node metastasis and tumor stage in patients with breast cancer. Functional analyses revealed that restoring miR-511 expression suppressed breast cancer cell proliferation and colony formation, promoted apoptosis and reduced metastasis in vitro, while it attenuated tumor growth in vivo. Additionally, it was revealed that SRY-box 9 (SOX9) was a direct target gene of miR-511 in breast cancer cells. SOX9 was upregulated in breast cancer tissues and its expression was inversely correlated with that of miR-511. Furthermore, SOX9 inhibition simulated the tumor-suppressive roles of miR-511 overexpression in breast cancer cells, while SOX9 reintroduction partially rescued these effects of miR-511. Notably, the upregulation of miR-511 targeted SOX9 to deactivate the PI3K/Akt signaling in breast cancer in vitro and in vivo. In conclusion, miR-511 was downregulated in breast cancer, and impeded its malignant
\end{abstract}

Correspondence to: Professor Yuying Zhao, Department of Medical Oncology, The Fourth Affiliated Hospital of Harbin Medical University, 37 Yiyuan Road, Harbin, Heilongjiang 150001, P.R. China

E-mail: yyzhao_harbin@163.com

Key words: microRNA-511, breast cancer, SRY-box phosphoinositide 3-kinase/Akt serine/threonine kinase pathway progression by directly targeting SOX 9 and regulating the PI3K/Akt pathway. Thus, miR-511 is a potential therapeutic target in breast canc

\section{Introduction}

Breast cancer is the most common malignant tumor and the second leading cause of cancer-associated death among women worldwide (1). In 2012, 1.7 million diagnoses and 521,900 mortalities accounting for $25 \%$ of cancer cases and $15 \%$ of cancer-associated mortalities, respectively, were reported (2). Multiple factors, including obesity, a high-fat diet, hormone replacement therapy, early menarche and late menopause, have been identified to be involved in breast cancer onset and development (3); however, the detailed molecular mechanisms remain unclear. At present, the major treatments for breast cancer patients are surgery in combination with hormonotherapy, chemoradiotherapy and/ or biological therapy (4). Despite significant progress in the early detection and therapy of breast cancer, the therapeutic outcomes of patients diagnosed at an advanced stage remain unsatisfactory $(5,6)$. Recurrence and metastasis are the primary causes of poor prognosis for patients with breast cancer (7). Therefore, characterization of the molecular footprint of breast cancer is urgently required to identify promising therapeutic targets for the management of patients with this disease.

MicroRNAs (miRNAs/miRs) are a group of endogenous, non-coding, short RNA molecules that are 19-24 nucleotides in length (8). Currently, $>2,000$ mature miRNAs have been identified in the human genome, and these miRNAs regulate gene expression by directly binding to a 'seed sequence' within the 3'-untranslated region (UTR) of each target gene, resulting in translational suppression and/or mRNA destabilization (9). It has been demonstrated that a single miRNA can modulate numerous target genes, and $>50 \%$ of known miRNAs are located at cancer-associated chromosomal regions, suggesting that miRNAs may have crucial roles in tumorigenesis and tumor development (10). Recent studies have revealed the aberrant expression of various miRNAs in breast cancer, and their deregulation has been implicated in breast cancer genesis and development (11-13). Deregulated miRNAs can have oncogenic 9, or tumor-suppressive roles in breast cancer and control biological behaviors, including cell proliferation, cell cycle, apoptosis, invasion, metastasis, epithelial-mesenchymal transition and 
angiogenesis (14-16). Therefore, further investigations of the biological functions of miRNAs may help us to better understand the mechanisms underlying breast cancer formation/progression and facilitate the development of attractive therapeutic approaches.

miR-511 has been identified to be deregulated in diverse human cancer types, including colorectal cancer (17), gastric cancer (18), lung adenocarcinoma (19) and hepatocellular carcinoma (20). miR-511 has been revealed as an important gene expression regulator in breast cancer (21). However, neither the expression status nor the detailed roles of miR-511 in breast cancer have been clarified. In this study, it was aimed to determine the expression of miR-511 in breast cancer, test its role in malignant progression and explore downstream targets. SRY-box 9 (SOX9) was predicted as a potential target of miR-511 and was chosen for further investigation as this gene was previously reported to be upregulated in breast cancer and implicated in breast carcinogenesis and development (22-28). The findings indicate that miR-511 may be a molecular target for the treatment of patients with breast cancer.

\section{Materials and methods}

Tissue specimens. This study was approved by the Ethics Committee of The Fourth Affiliated Hospital of Harbin Medical University (Harbin, China) and each patient enrolled provided written informed consent. Pairs of breast cancer tissues and adjacent normal breast tissues $(n=51)$ were obtained at The Fourth Affiliated Hospital of Harbin Medical University between May 2014 and March 2017. Patients had been treated with preoperative adjuvant chemotherapy, radiotherapy or other therapy were excluded from this research. All tissue specimens were snap-frozen in liquid nitrogen and stored at $-80^{\circ} \mathrm{C}$ prior to RNA isolation.

Cell lines. A human breast epithelial cell line (MCF-10A) and four human breast cancer cell lines (MCF-7, BT-474, MDA-MB-231 and SKBR3) were purchased from Shanghai Institute of Biochemistry and Cell Biology (Shanghai, China). All the cell lines were cultured at $37^{\circ} \mathrm{C}$ in a $5 \% \mathrm{CO}_{2}$ incubator using Dulbecco'smodifiedEagle'smedium(DMEM)containing $10 \%$ fetal bovine serum (FBS) and $1 \%$ penicillin/streptomycin mixture (all from Gibco; Thermo Fisher Scientific, Inc., Waltham, MA, USA).

Oligonucleotide, small interfering RNA (siRNA) and plasmid transfection. miR-511 mimics and negative control miRNA mimics (miR-NC) were obtained from Shanghai GenePharma Co., Ltd. (Shanghai, China). The miR-511 mimics sequence was 5'-GUGUCUUUUGCUCUGCAGUCA-3' and the miR-NC sequence was 5'-UUCUCCGAACGUGUCACGUTT-3'. An siRNA targeting SOX9 and negative control siRNA (NC siRNA) were purchased from Guangzhou RiboBio (Guangzhou, China). The SOX9 siRNA sequence was 5'-AGCAAGTCCGCGAGCC AGTAC-3' and the NC siRNA sequence was 5'-UUCUCCGAA CGUGUCACGUTT-3'. The full-length SOX9 lacking the 3'-UTR sequence was chemically synthesized by the Chinese Academy of Sciences (Changchun, China) and inserted into the pcDNA3.1 vector to produce pcDNA3.1-SOX9 plasmid.

Cells were inoculated into 6-well plates at 60-70\% confluence. Following overnight incubation, cells were transfected with
miR-511 mimics (100 pmol), miR-NC (100 pmol), SOX9 siRNA (100 pmol), NC siRNA (100 pmol), pcDNA3.1-SOX9 (4 $\mu \mathrm{g})$ or empty pcDNA3.1 vector $(4 \mu \mathrm{g})$ using Lipofectamine ${ }^{\circledR} 2000$ (Thermo Fisher Scientific, Inc.) in accordance with the manufacturer's protocol. Reverse transcription-quantitative polymerase chain reaction (RT-qPCR) was utilized to determine the transfection efficiency of miR-511 mimics. The transfection efficiencies of SOX9 siRNA and pcDNA3.1-SOX9 were evaluated by western blot analysis after $72 \mathrm{~h}$ of incubation.

$R N A$ extraction and $R T-q P C R$. TRIzol ${ }^{\circledR}$ reagent (Thermo Fisher Scientific, Inc.) was used to isolate total RNA from tissue specimens or cultured cells. For the quantification of miR-511 expression, first-strand cDNA synthesis was performed using the miScript Reverse Transcription kit (Qiagen $\mathrm{GmbH}$, Hilden, Germany) following the manufacturer's protocol. Subsequently, qPCR was performed using the miScript SYBR ${ }^{\circledR}$-Green PCR kit (Qiagen $\mathrm{GmbH}$ ). The thermocycling conditions for $\mathrm{qPCR}$ were as follows: $95^{\circ} \mathrm{C}$ for $15 \mathrm{~min}$, followed by 45 cycles of $94^{\circ} \mathrm{C}$ for $15 \mathrm{sec}$, $55^{\circ} \mathrm{C}$ for $30 \mathrm{sec}$ and $70^{\circ} \mathrm{C}$ for $30 \mathrm{sec}$. miR-511 expression was normalized to that of 66 small nuclear RNA. To analyze the mRNA expression of SOX9, RT was conducted using the PrimeScript ${ }^{\mathrm{TM}}$ RT reagent kit, and the synthesized cDNA was then subjected to qPCR using a SYBR ${ }^{\circledR}$ Premix Ex Taq ${ }^{\mathrm{TM}}$ kit (both from Takara Biotechnology Co., Ltd., Dalian, China).qPCR for mRNA was performed with the following cycling conditions: $5 \mathrm{~min}$ at $95^{\circ} \mathrm{C}$, followed by 40 cycles of $95^{\circ} \mathrm{C}$ for $30 \mathrm{sec}$ and $65^{\circ} \mathrm{C}$ for $45 \mathrm{sec}$. GAPDH was used as an internal reference for the mRNA expression of SOX9. The primers were designed as follows: miR-511, 5'-GTGTCTTTTGCTCTGCAGTC-3' (forward) and 5'-AACATGTACAGTCCATGGATG-3' (reverse); U6, 5'-GCTTCGGCAGCACATATACTAAAAT-3' (forward) and 5'-CGCTTCACGAATTTGCGTGTCAT-3' (reverse); SOX9, 5'-CTGGGAACAACCCGTCTA-3' (forward) and 5'-GGGTAA TGCGCTTGGATA-3' (reverse); and GAPDH, 5'-CGGAGTCA ACGGATTTGGTCGTAT-3' (forward) and 5'-AGCCTTCTCC ATGGTGGTGAAGAC-3' (reverse). Relative gene expression was analyzed using the $2^{-\Delta \Delta C q}$ method (29).

Cell counting kit 8 (CCK-8) assay. Transfected cells were collected at $24 \mathrm{~h}$ post-transfection and seeded into 96 -well plates with an initial density of $3 \times 10^{3}$ cells per well. Cells were then incubated at $37^{\circ} \mathrm{C}$ under $5 \% \mathrm{CO}^{2}$ for $0,24,48$ or $72 \mathrm{~h}$. At each time point, the CCK- 8 assay was performed by adding $10 \mu \mathrm{l} \mathrm{CCK}-8$ solution (Dojindo Molecular Technologies, Inc., Kumamoto, Japan) into each well. After another $2 \mathrm{~h}$ incubation with CCK-8 reagent at $37^{\circ} \mathrm{C}$, the optical density was detected at $450 \mathrm{~nm}$ wavelength using a SpectraMax ${ }^{\circledR}$ microplate spectrophotometer (Molecular Devices, LLC, Sunnyvale, CA, USA).

Colony formation assay. The colony formation assay was applied to assess the ability of breast cancer cells to form colonies. Following $24 \mathrm{~h}$ incubation, transfected cells were harvested, and single cells were plated into 6-well plates with a density of 1,000 cells per well. Cells were maintained at $37^{\circ} \mathrm{C}$ supplied with $5 \% \mathrm{CO}_{2}$ for 2 weeks. On day 15 , cells were fixed with $4 \%$ paraformaldehyde, stained with methyl violet (Beyotime Institute of Biotechnology, Haimen, China) and washed with PBS. The number of colonies was counted under an inverted microscope (IX83; Olympus, Tokyo, Japan). 
Flow cytometry analysis of cell apoptosis. An Annexin V-fluorescein isothiocyanate (FITC) apoptosis detection kit (Biolegend, Inc., San Diego, CA, USA) was used to measure the apoptosis rate of breast cancer cells. Cells were collected at $48 \mathrm{~h}$ after transfection, washed three times with cold PBS and resuspended in $100 \mu \mathrm{l}$ binding buffer. Subsequently, cells were double-stained at $37^{\circ} \mathrm{C}$ with $5 \mu \mathrm{l}$ Annexin V-FITC and $5 \mu \mathrm{l}$ propidium iodide for $30 \mathrm{~min}$ in the dark. The percentage of apoptotic cells was measured using a flow cytometer $\left(\mathrm{FACScan}^{\mathrm{TM}}\right.$; BD Biosciences, Franklin Lakes, NJ, USA). The data were processed using CellQuest ${ }^{\mathrm{TM}}$ version 5.1 software (BD Biosciences).

Migration and invasion assays. The migratory and invasive abilities of breast cancer cells were investigated using 24-well Transwell ${ }^{\circledR}$ inserts (pore size, $8 \mu \mathrm{m}$ ) coated without or with Matrigel ${ }^{\circledR}$ (both from BD Biosciences). In brief, a single-cell suspensions of the transfected cells was prepared and $1 \times 10^{5}$ cells in $200 \mu \mathrm{FBS}$-free DMEM were added to the upper compartment of Transwell ${ }^{\circledR}$ inserts. DMEM supplemented with $10 \%$ FBS was added into the lower compartment to serve as a chemo-attractant. After $24 \mathrm{~h}$ of incubation at $37^{\circ} \mathrm{C}$ with $5 \% \mathrm{CO}_{2}$, the cells were fixed with $4 \%$ paraformaldehyde at room temperature for $20 \mathrm{~min}$ and stained with $0.05 \%$ crystal violet (Beyotime Institute of Biotechnology) at room temperature for $20 \mathrm{~min}$. The non-migrated or non-invading cells were carefully removed using a cotton swab, while the number of migrated or invaded cells was counted in five randomly chosen visual fields under an inverted microscope

Xenograft tumor experiment. All animal experiments were performed in accordance with the Guide for the Care and Use of Laboratory Animals and approved by the Ethics Review Committee of The Fourth Affiliated Hospital of Harbin Medical University. Cells were transfected with miR-511 mimics or miR-NC and incubated at $37^{\circ} \mathrm{C}$ under $5 \% \mathrm{CO}_{2}$ for $24 \mathrm{~h}$. Transfected cells were harvested after $24 \mathrm{~h}$ of incubation and then subcutaneously administered into the hind flanks of 4 -week-old BALB/c nude mice ( $1 \times 10^{6}$ cells per mouse). Tumor width and length were detected every 4 days for 4 weeks. All nude mice were sacrificed 4 weeks after tumor implantation and the tumor xenografts were excised and weighed. The tumor volumes were calculated using the equation: Tumor volume $=0.5 \mathrm{x}$ tumor length $\mathrm{x}$ tumor width .

Bioinformatics analysis. TargetScan 7.1 (http://www.targetscan. org/) and MiRanda (http://www.microrna.org/) were used to predict the potential targets of miR-511. SOX9 was identified as a candidate target gene of miR-511.

Plasmidconstructionandluciferasereporterassay. The 3'-UTR of SOX9 containing the wild-type or mutant miR-511 binding site was amplified by Shanghai GenePharma and inserted into the pMIR-REPORT plasmid (Promega Corporation, Madison, WI, USA). Cells were plated into 24 -well plates with a density of $1 \times 10^{5}$ cells/well and were co-transfected with the luciferase reporter plasmid $(0.2 \mu \mathrm{g})$ together with miR-511 mimics $(50 \mathrm{pmol})$ or miR-NC (50 pmol) using Lipofectamine ${ }^{\circledR} 2000$. Luciferase activity was determined $48 \mathrm{~h}$ after transfection using the dual-luciferase reporter assay system (Promega
Corporation). Renilla luciferase activity served as an internal reference for Firefly luciferase activity.

Western blot analysis. Cells or tissues were lysed in ice-cold radioimmunoprecipitation buffer (Cell Signaling Technology, Inc., Danvers, MA, USA) to extract total protein. The concentration of the isolated total protein was detected using a bicinchoninic acid assay kit (Beyotime Institute of Biotechnology). Equal amounts $(30 \mu \mathrm{g})$ of protein were separated by SDS-PAGE on a $10 \%$ polyacrylamide gel. The separated proteins were then electronically transferred onto polyvinylidene difluoride membranes (EMD Millipore, Billerica, MA, USA). Following blocking at room temperature in $5 \%$ fat-free milk powder for $2 \mathrm{~h}$, the membranes were incubated overnight at $4{ }^{\circ} \mathrm{C}$ with primary antibodies against SOX9 (cat. no. ab185966, 1:1,000 dilution), phospho (p)-phosphoinositide 3-kinase (PI3K; cat. no. ab182651; 1:1,000 dilution), PI3K (cat. no. ab191606; 1:1,000 dilution) (all from Abcam, Cambridge, UK), p-Akt (cat. no. sc-81433; 1:1,000 dilution), Akt (cat. no. sc-56878; 1:1,000 dilution) (both from Santa Cruz Biotechnology, Inc., Dallas, TX, USA) or GAPDH (cat. no. ab181603; 1:1,000 dilution; Abcam). Following three washes with Tris-buffered saline containing $0.1 \%$ Tween ${ }^{\circledR}$ 20 , the membranes were further incubated with the goat anti-rabbit (cat. no. ab6721; Abcam; used for SOX9, p-PI3K, PI3K and GAPDH primary antibodies) or goat anti-mouse (cat. no. ab205719; Abcam; used for p-Akt and Akt primary antibodies) corresponding horseradish peroxidase-conjugated secondary antibody (both 1:5,000 dilution) at room temperature for $2 \mathrm{~h}$ and visualized using an enhanced chemiluminescence kit (EMD Millipore). GAPDH was used as a loading control. Protein expression was quantified using Quantity One software version 4.62 (Bio-Rad Laboratories, Inc., Hercules, CA, USA).

Statistical analysis. SPSS software (version 19.0; IBM Corp., Armonk, NY,USA) was used to perform all statistical analyses. Data are presented as the mean \pm standard deviation from three independent experiments. The statistical differences between groups were analyzed using Student's t-test or one-way analysis of variance combined with multiple comparisons using the Student-Newman-Keuls post-hoc test. The $\chi^{2}$ test was used to assess the association between miR-511 expression and the clinicopathological features of patients with breast cancer. Spearman's correlation analysis was employed to identify the association between the expression levels of miR-511 and SOX9 mRNA in breast cancer tissues. $\mathrm{P}<0.05$ was considered to indicate a statistically significant difference.

\section{Results}

miR-511 is downregulated in breast cancer tissues and cell lines. To determine the expression of miR-511 in breast cancer, miR-511 expression was detected using RT-qPCR in 51 pairs of breast cancer tissue and adjacent normal breast tissue. miR-511 was significantly reduced in breast cancer tissues compared with adjacent normal breast tissues $(\mathrm{P}<0.05$; Fig. 1A). To further confirm this observation, miR-511 expression was analyzed in four human breast cancer cell lines (MCF-7, BT-474, MDA-MB-231 and SKBR3) and a human breast epithelial cell line (MCF-10A). The expression of miR-511 was 

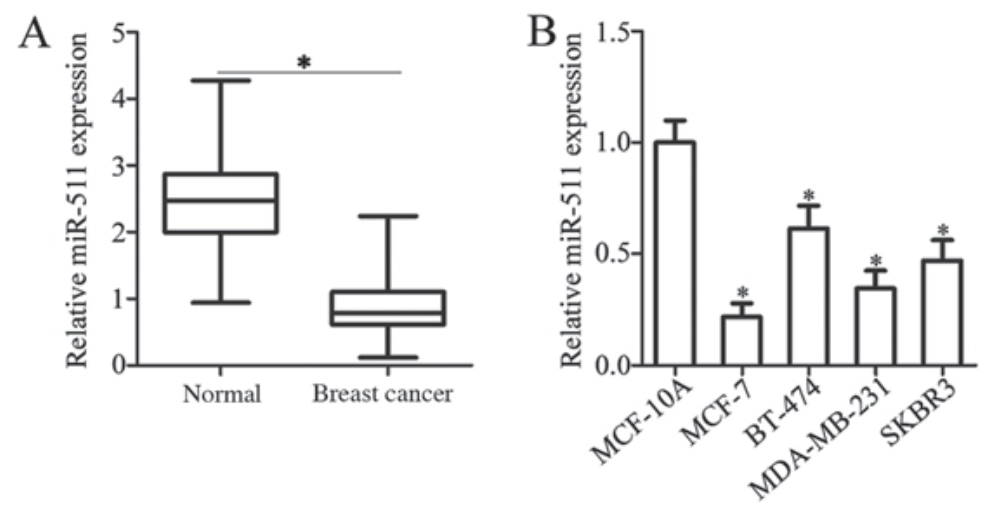

Figure 1. miR-511 expression is reduced in breast cancer tissues and cell lines. (A) The expression of miR-511 was determined in 51 pairs of breast cancer tissues and adjacent normal breast tissues using RT-qPCR. "P<0.05. (B) RT-qPCR was used to detect miR-511 expression in four human breast cancer cell lines (MCF-7, BT-474, MDA-MB-231 and SKBR3) and a human breast epithelial cell line (MCF-10A). "P<0.05 vs. MCF-10A. RT-qPCR, reverse transcription-quantitative polymerase chain reaction; miR, microRNA.

Table I. Association between miR-511 expression in tumor tissue and clinical characteristics of patients with breast cancer.

\begin{tabular}{lccc}
\hline & \multicolumn{2}{c}{ miR-511 expression } & \\
\cline { 2 - 3 } Clinical characteristics & Low & High & P-value \\
\hline Age (years) & & & 0.447 \\
$<50$ & 11 & 8 & \\
$\geq 50$ & 15 & 17 & \\
Tumor diameter (cm) & & & 0.329 \\
$<2$ & 8 & 11 & \\
$\geq 2$ & 18 & 14 & 0.461 \\
Histology grade & & & \\
I-II & 12 & 9 & $0.001^{\mathrm{a}}$ \\
III & 14 & 16 & \\
Lymph node metastasis & & & \\
Negative & 9 & 20 & $0.017^{\mathrm{a}}$ \\
Positive & 17 & 5 & \\
Tumor stage & & & \\
I-II & 7 & 15 & \\
III & 19 & 10 & \\
\hline
\end{tabular}

${ }^{a} \mathrm{P}<0.05$. The median value of miR-511 in tumor tissues was used to divide the samples in high and low expression groups. miR, microRNA.

significantly lower in all four breast cancer cell lines compared with MCF-10A cells ( $\mathrm{P}<0.05$; Fig. 1B).

miR-511 expression is associated with the clinical characteristics of patients with breast cancer. To characterize the clinical characteristics of miR-511, all patients with breast cancer were divided into either the miR-511 low expression group $(n=26)$ or miR-511 high expression group $(n=25)$ based on the median value of miR-511. The results of the statistical analysis indicated that decreased miR-511 expression was associated with lymph node metastasis $(\mathrm{P}=0.001)$ and tumor stage $(\mathrm{P}=0.017$; Table I). However, no significant associations were observed between miR-511 expression and other clinicopathological characteristics, including age, tumor diameter and histology grade (all $\mathrm{P}>0.05$ ). The results suggest that the downregulation of miR-511 may be involved in breast cancerinitiation and progression.

miR-511 upregulation inhibits proliferation, promotes apoptosis, and decreases metastasis in breast cancer cells in vitro. To gain insight into the detailed roles of miR-511 in breast cancer, miR-511 mimics were transfected into MCF-7 and MDA-MB-231 cells to increase endogenous miR-511 expression. The data obtained by RT-qPCR analysis revealed that miR-511 was overexpressed in miR-511 mimics-transfected MCF-7 and MDA-MB-231 cells relative to that in cells transfected with miR-NC $(\mathrm{P}<0.05$; Fig. 2A). The CCK-8 assay was performed to evaluate the effect of miR-511 upregulation on the proliferative ability of breast cancer cells. Ectopic miR-511 expression caused an obvious reduction in proliferation in MCF-7 and MDA-MB-231 cells $(\mathrm{P}<0.05$; Fig. 2B). Colony formation assay was also used to confirm the regulatory effect of miR-511 on breast cancer cell proliferation. The results indicated that miR-511 overexpression significantly decreased the colony formation abilities of MCF-7 and MDA-MB-231 cells ( $\mathrm{P}<0.05$; Fig. 2C). Apoptosis is associated with the alterations in cell proliferation, suggesting that a high apoptosis rate mat cause suppression of cell proliferation. Thus, the apoptosis rate of MCF-7 and MDA-MB-231 cells transfected with miR-511 mimics or miR-NC was determined. As displayed in Fig. 2D, enforced miR-511 expression increased the rate of apoptosis in MCF-7 and MDA-MB-231 cells in comparison with the miR-NC groups $(\mathrm{P}<0.05)$. Furthermore, migration and invasion assays were performed to determine whether miR-511 was involved in the regulation of breast cancer cell metastasis. miR-511-overexpressing MCF-7 and MDA-MB-231 cells exhibited decreased migratory $(\mathrm{P}<0.05$; Fig. $2 \mathrm{E})$ and invasive $(\mathrm{P}<0.05$ : Fig. $2 \mathrm{~F})$ capacities as compared with the cells transfected with miR-NC. The findings suggest that miR-511 upregulation may inhibit the aggressiveness of breast cancer cells.

SOX9 is a direct target of miR-511 in breast cancer cells. To elucidate the mechanism by which miR-511 may act as a tumor suppressor in breast cancer, bioinformatics analysis was performed to search for putative targets of miR-511. SOX9 was predicted to be a major target of miR-511, as two complementary binding sites of miR-511 were identified in the 3'-UTR of the 
A

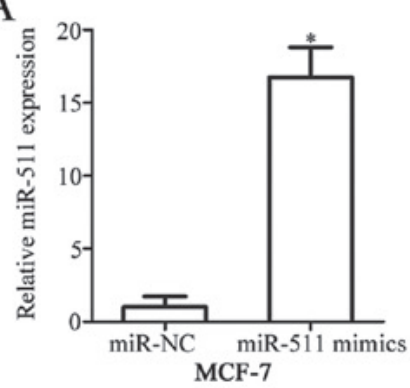

C

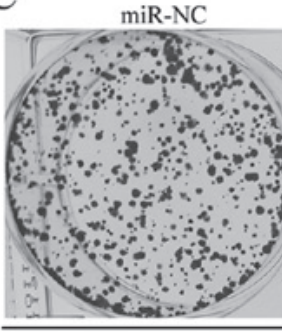

miR-511 mimics

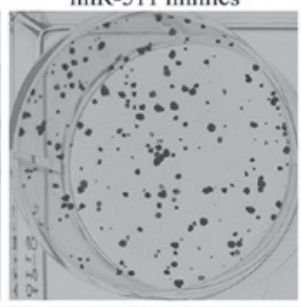

MCF-7

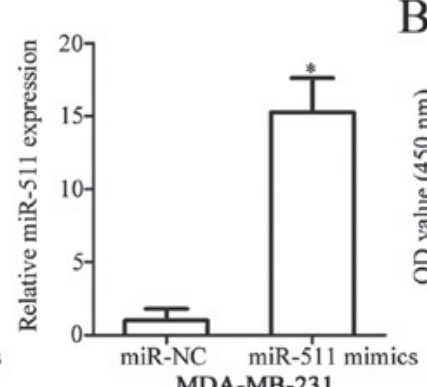

MDA-MB-231

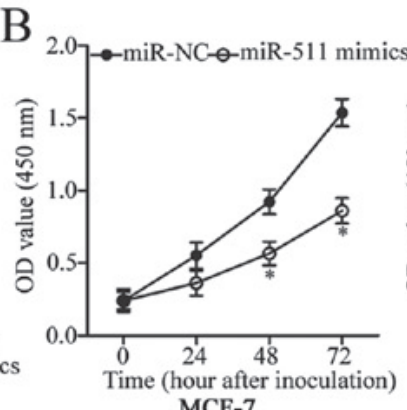

MCF-7
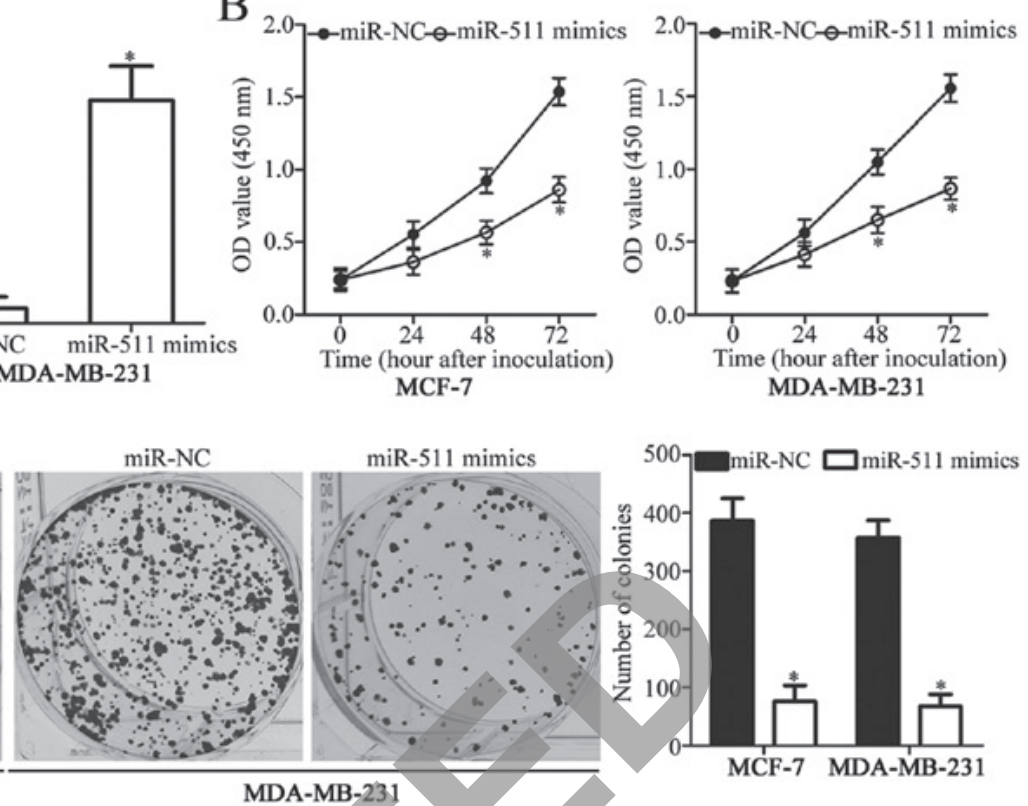

D
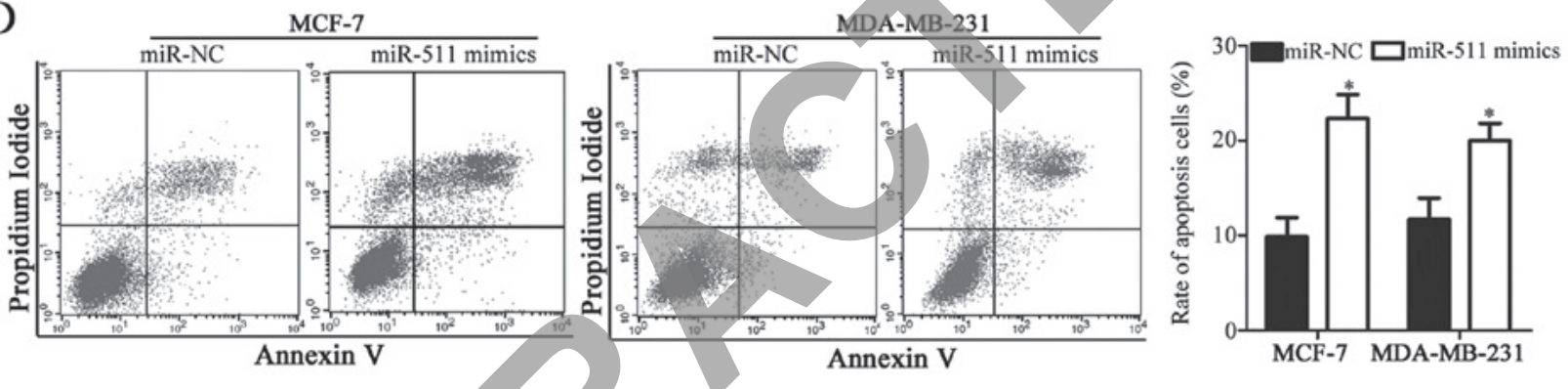

$\mathrm{E}$

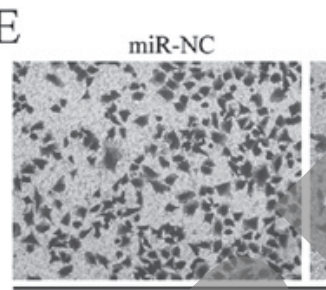

miR-511 mimics

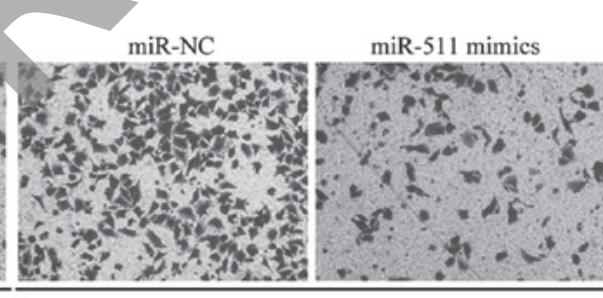

MDA-MB-231

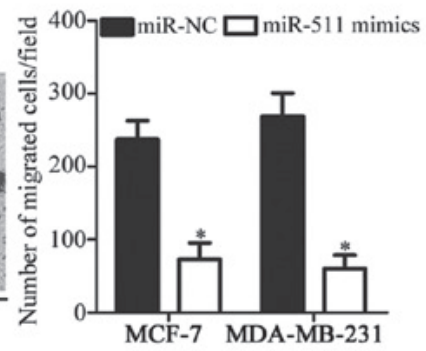

$\mathrm{F}$

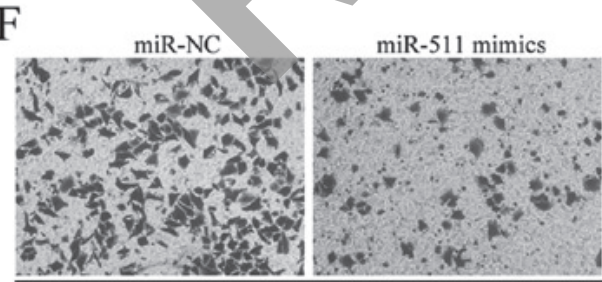

MCF-7

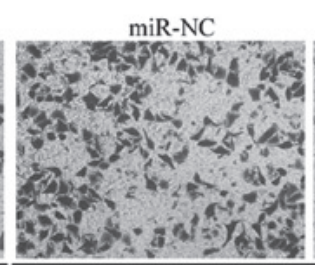

MDA-MB-231 miR-511 mimics

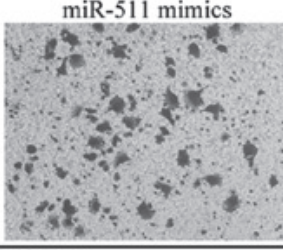

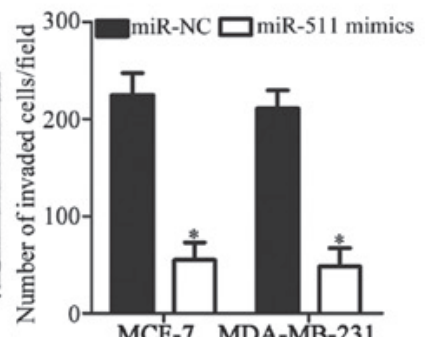

Figure 2. miR-511 is involved in the regulation of breast cancer cell proliferation, colony formation, apoptosis, migration and invasion in vitro. MCF-7 and MDA-MB-231 cells were transfected with miR-511 mimics or miR-NC. (A) miR-511 expression in MCF-7 and MDA-MB-231 cells following transfection with miR-511 mimics compared with that in cells transfected with miR-NC. (B) CCK-8 and (C) colony formation assays were performed to assess the proliferative and colony formation capacities of the cells. (D) Apoptosis of MCF-7 and MDA-MB-231 cells following transfection with miR-511 mimics or miR-NC was measured using flow cytometry analysis. (E) Migration and (F) invasion of MCF-7 and MDA-MB-231 cells were transfected with miR-511 mimics or miR-NC determined using migration and invasion assays. " $\mathrm{P}<0.05$ vs. miR-NC. miR, microRNA; NC, negative control; OD, optical density.

SOX9 gene (Fig. 3A). SOX9 was chosen for further experimental confirmation as this gene was previously reported to be involved in the pathogenesis of breast cancer. A luciferase reporter assay was performed to determine whether miR-511 directly recognized and bound to the 3'-UTR of SOX9. The data revealed that miR-511 upregulation decreased the luciferase activity of the plasmid harboring the wild-type (1 and 2) 3'-UTR of SOX9 in MCF-7 and MDA-MB-231 cells ( $\mathrm{P}<0.05$; Fig. 3B), but did not 
A

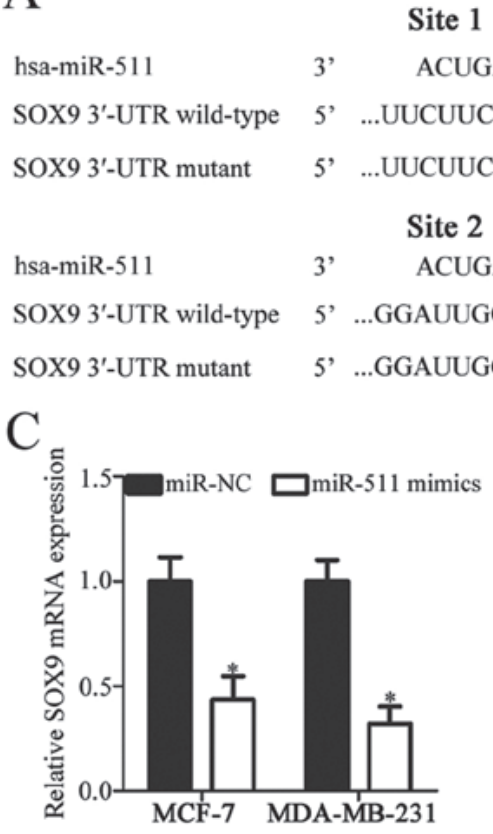

B

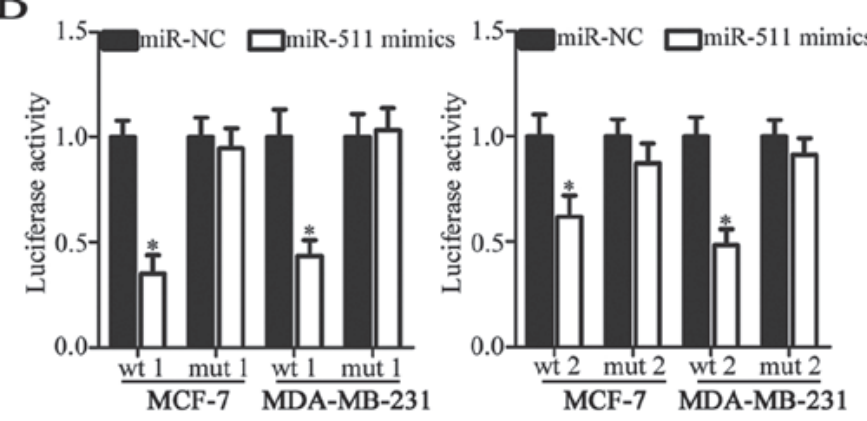

Figure 3. miR-511 inhibits SOX9 expression by directly binding to its 3'-UTR in breast cancer cells. (A) Predicted sequences that enable binding between miR-511 and the 3'-UTR of SOX9 gene through complementary base pairing. (B) Luciferase reporter plasmids carrying the wild-type or mutant miR-511 binding sequences in the 3'-UTR of SOX9 were chemically synthesized and were co-transfected with miR-511 mimics or miR-NC in MCF-7 and MDA-MB-231 cells. After transfection for $48 \mathrm{~h}$, luciferase activities were detected using the dual-luciferase reporter assay system. (C) mRNA and (D) protein levels of SOX9 in MCF-7 and MDA-MB-231 cells transfected with miR-511 mimics or miR-NC were detected via reverse transcription-quantitative polymerase chain reaction and western blot analysis, respectively. ${ }^{*} \mathrm{P}<0.05$ vs. miR-NC. UTR, untranslated region; SOX, SRY-box 9; miR, microRNA; NC, negative control; wt, wild-type; mut, mutant.

D
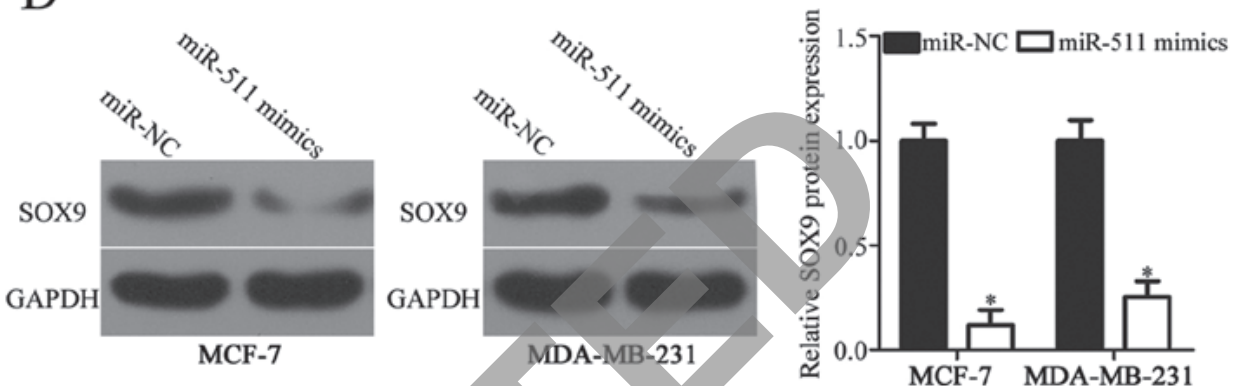

wh
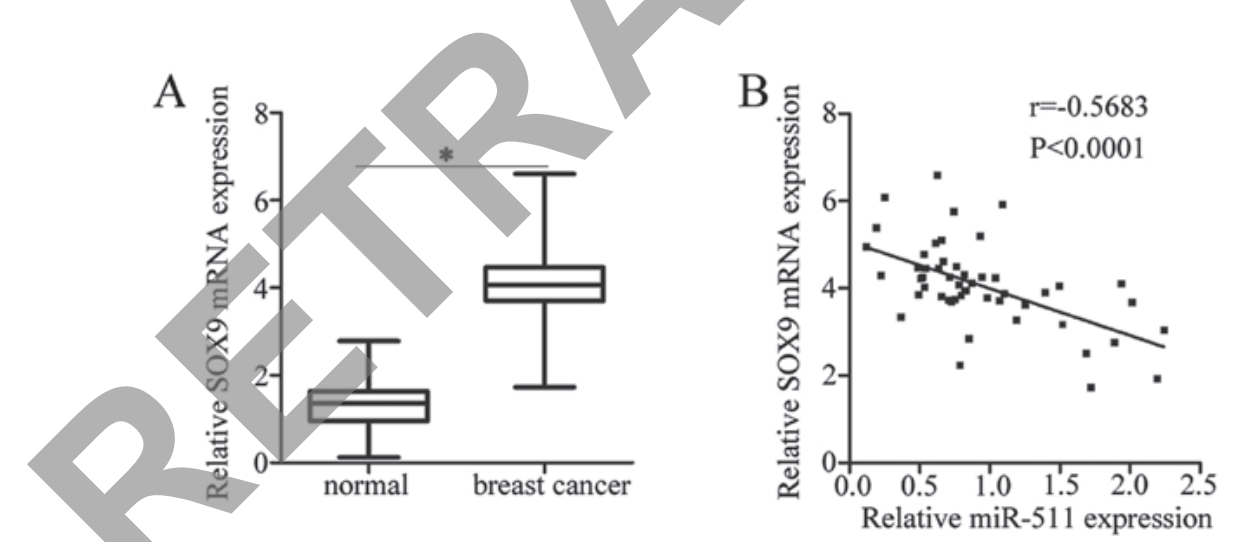

Figure 4. Inverse correlation between miR-511 and SOX9 mRNA levels in breast cancer tissues. (A) Reverse transcription-quantitative polymerase chain reaction analysis of SOX 9 mRNA expression in 51 pairs of breast cancer tissues and adjacent normal breast tissues. ${ }^{*} \mathrm{P}<0.05$. (B) Negative correlation between miR-511 and SOX9 mRNA levels in breast cancer tissues analyzed by Spearman's correlation analysis. r=-0.5683, P<0.0001. SOX, SRY-box 9.

affect the activity of the mutant (1 and 2) 3'-UTR plasmid. To further confirm that SOX9 is a target of miR-511, RT-qPCR and western blot analysis were performed to detect SOX9 mRNA and protein expression in MCF-7 and MDA-MB-231 cells with overexpressed miR-511. The mRNA ( $\mathrm{P}<0.05$; Fig. $3 \mathrm{C})$ and protein $(\mathrm{P}<0.05$; Fig. 3D) levels of SOX9 were lowered in MCF-7 and MDA-MB-231 cells transfected with miR-511 mimics. Collectively, these findings suggest that SOX9 is a direct target gene of miR-511 in breast cancer cells.

SOX9 expression is negatively correlated with $\mathrm{miR}-511$ expression in breast cancer tissues. To further illustrate the relationship between miR-511 and SOX9 in breast cancer, RT-qPCR was performed to measure SOX9 expression in breast cancer tissues and adjacent normal breast tissues. Compared with adjacent normal breast tissues, the level of SOX9 mRNA ( $\mathrm{P}<0.05$; Fig. 4A) was strikingly upregulated in breast cancer tissues. Then, Spearman's correlation analysis was performed to analyze the association between miR-511 and SOX9 expression in breast cancer tissues, which revealed a statistically significant negative correlation between the miR-511 and SOX9 mRNA levels in these breast cancer tissues ( $\mathrm{r}=-0.5683, \mathrm{P}<0.0001$; Fig. 4B). These results further supported the conclusion that SOX9 is a downstream target of miR-511 in breast cancer.

SOX9 knockdown imitates the tumor-suppressor activity of miR-511 upregulation in breast cancer cells. SOX9 was 
A

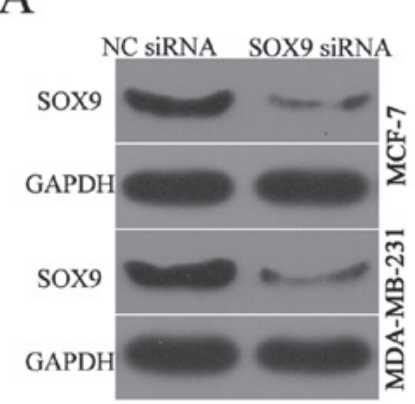

B

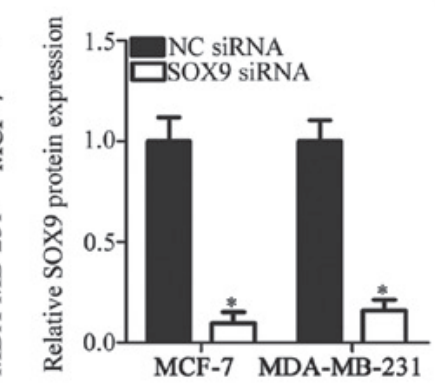

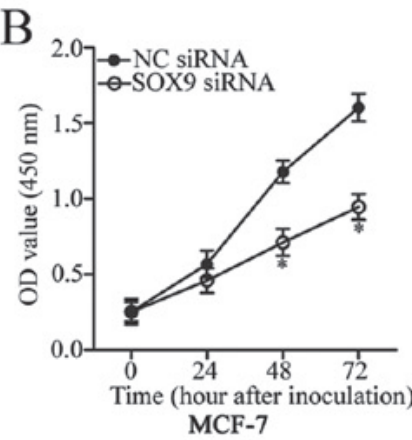

MCF-7

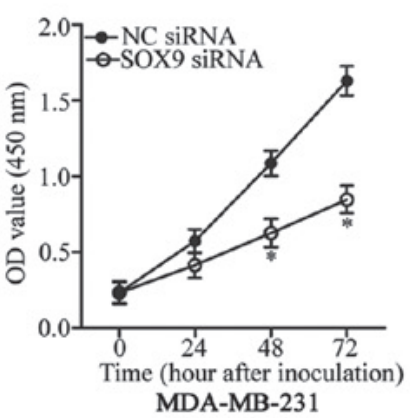

MDA-MB-231

C

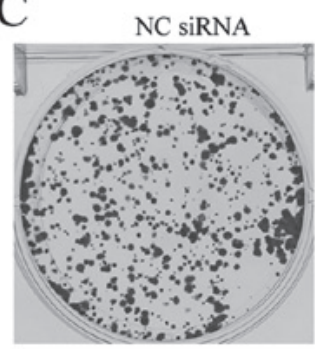

SOX9 SiRNA
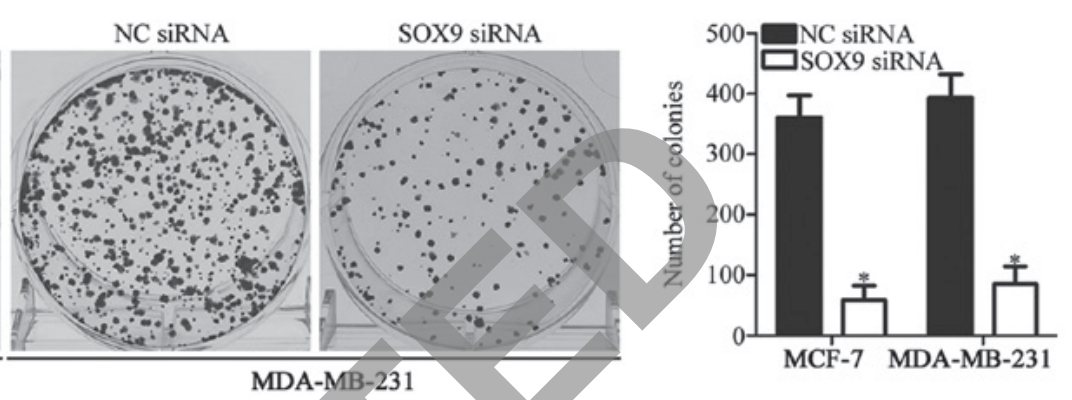

D
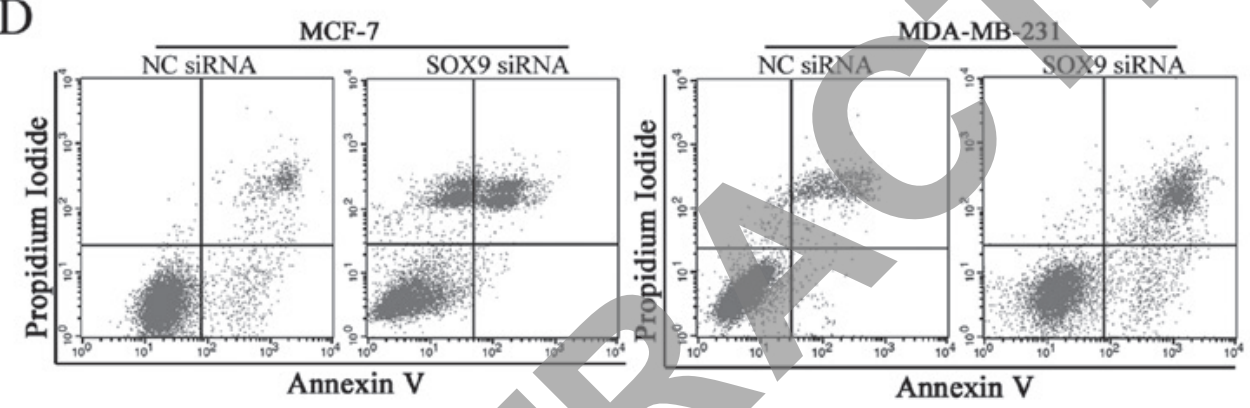

E
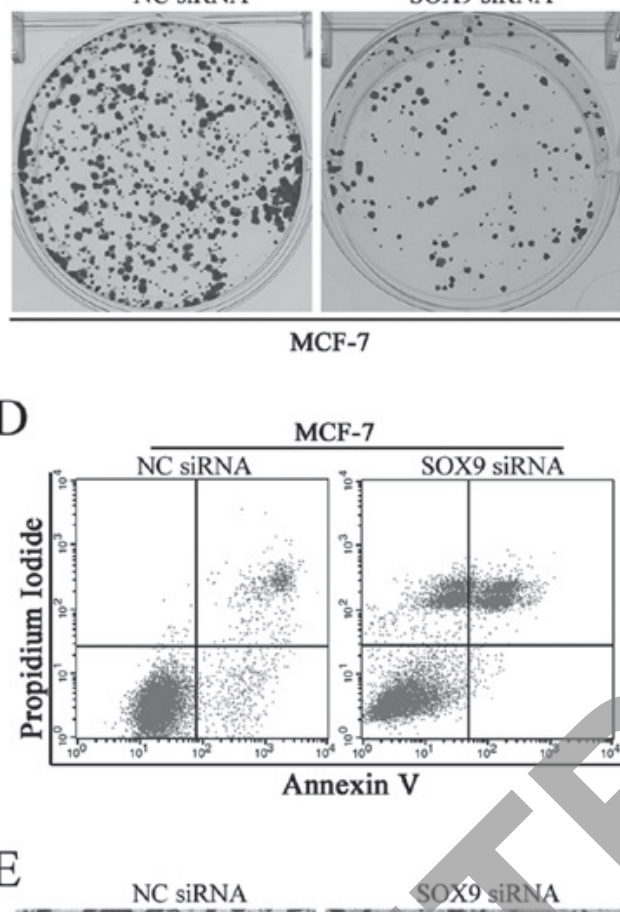

MCF-7

Annexin V

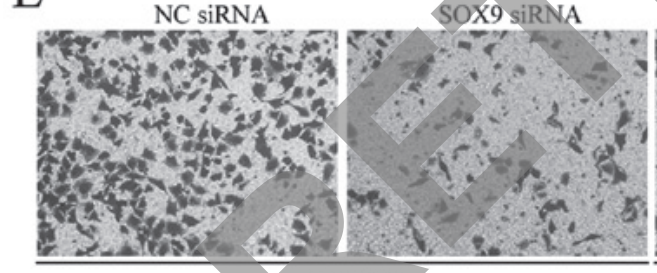

MCF-7

$\mathrm{F}$

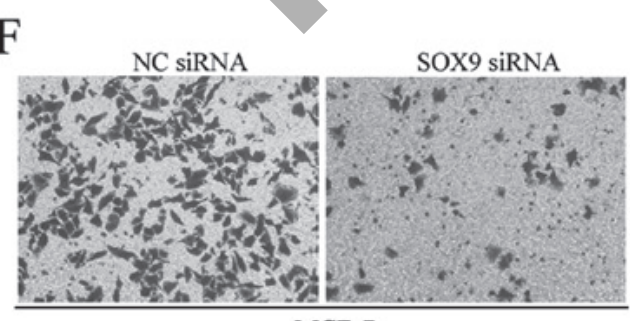

MCF-7

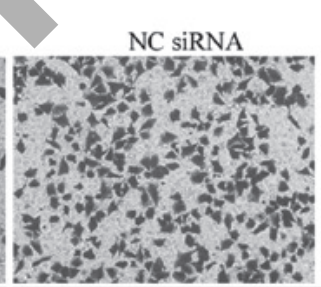

MDA-MB-231

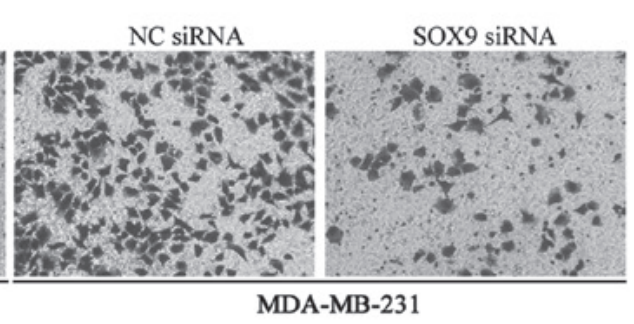

SOX9 siRNA

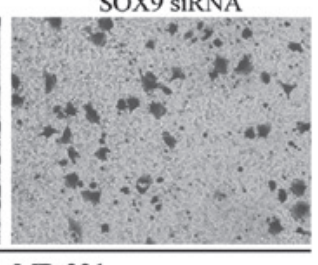

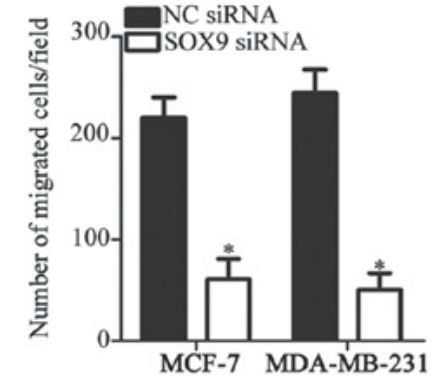

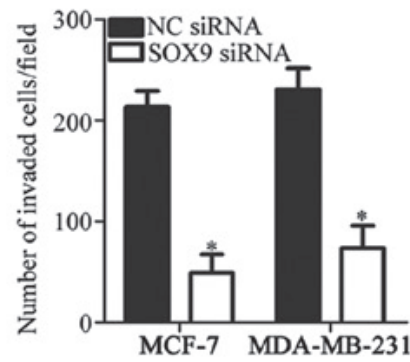

Figure 5. SOX9 inhibition suppresses MCF-7 and MDA-MB-231 cell proliferation, colony formation, and metastasis while inducing apoptosis in vitro. (A) SOX9 protein was detected by western blot analysis in MCF-7 and MDA-MB-231 cells transfected with SOX9 siRNA or NC siRNA. (B) CCK-8 assay, (C) colony formation assay and (D) flow cytometry analysis were performed to assess the proliferation, colony formation and apoptosis of MCF-7 and MDA-MB-231 cells, respectively, following transfection with SOX9 siRNA or NC siRNA. (E) Migration and (F) invasion assays were used to examine the migratory and invasive abilities of MCF-7 and MDA-MB-231 cells treated as described. "P<0.05 vs. NC siRNA. NC, negative control; siRNA, small interfering RNA; SOX, SRY-box 9.

validated as a direct target gene of miR-511 in breast cancer cells; thus, it was hypothesized that SOX9 knockdown may mimic the tumor-suppressor role of miR-511 overexpression in breast cancer cells. To test this hypothesis, SOX9 siRNA was applied to knock down endogenous SOX9 expression in MCF-7 and MDA-MB-231 cells ( $\mathrm{P}<0.05$; Fig. 5A). Subsequent 
functional assays demonstrated that SOX9 inhibition impeded proliferation $(\mathrm{P}<0.05$; Fig. $5 \mathrm{~B})$ and colony formation $(\mathrm{P}<0.05$; Fig. 5C), increased apoptosis $(\mathrm{P}<0.05$; Fig. 5D) and prohibited migration $(\mathrm{P}<0.05$; Fig. $5 \mathrm{E})$ and invasion $(\mathrm{P}<0.05$; Fig. 5F) of MCF-7 and MDA-MB-231 cells. Thus, the downregulation of SOX9 had functional effects that were similar to those of miR-511 upregulation in breast cancer cells, suggesting that SOX9 is a functional target of miR-511 in breast cancer cells.

RestoredSOX9 expressionpartiallyrelieves themiR-511-mediated suppression of breast cancer progression in vitro. To further demonstrate whether SOX9 inhibition was essential for the tumor-suppressor activity of miR-511 in breast cancer, a SOX9 overexpression plasmid lacking the 3'-UTR (pcDNA3.1-SOX9) was transfected into miR-511-overexpressing MCF-7 and MDA-MB-231 cells. Western blot analysis indicated that the downregulation of SOX9 protein caused by miR-511 upregulation was re-established in MCF-7 and MDA-MB-231 cells following co-transfection with pcDNA3.1-SOX9 (P<0.05; Fig. 6A). CCK-8 and colony formation assays revealed that $\mathrm{SOX} 9$ reintroduction re-established the miR-511-induced inhibition of MCF-7 and MDA-MB-231 cell proliferation ( $\mathrm{P}<0.05$; Fig. $6 \mathrm{~B})$ and colony formation $(\mathrm{P}<0.05$; Fig. $6 \mathrm{C})$. Additionally, the miR-511 mimics-mediated promotion of cell apoptosis was partially reversed by SOX9 restoration in MCF-7 and MDA-MB-231 cells $(\mathrm{P}<0.05$; Fig. 6D). Furthermore, the restoration of SOX9 overexpression blunted the inhibitory effects of miR-511 overexpression on the migratory $(\mathrm{P}<0.05$; Fig. $6 \mathrm{E})$ and invasive $(\mathrm{P}<0.05$; Fig. 6F) abilities of MCF-7 and MDA-MB-231 cells. Together, these results provided sufficient evidence to demonstrate that miR-511 may inhibit the development of breast cancer cells, at least partially by suppressing SOX 9 expression.

miR-511 inhibits the activation of the PI3K/Akt signaling pathway in breast cancer cells by targeting SOX9. SOX9 participates in the regulation of the PI3K/Akt signaling pathway $(30,31)$; thus, whether miR-511 inactivates PI3K/Akt signaling in breast cancer cells was examined. To test this hypothesis, western blot analysis was performed to detect the molecules associated with the PI3K/Akt pathway in MCF-7 and MDA-MB-231 cells following co-transfection with miR-511 mimics and pcDNA3.1 or pcDNA3.1-SOX9. It was demonstrated that enforced miR-511 expression suppressed the levels of the p-PI3K and p-Akt phosphoproteins in MCF-7 and MDA-MB-231 cells; however, miR-511 overexpression did not affect the total levels of the PI3K and Akt proteins. Additionally, co-transfection with pcDNA3.1-SOX9 restored the miR-511 overexpression-inhibited levels of $\mathrm{p}-\mathrm{PI} 3 \mathrm{~K}$ and p-Akt in these cell lines (Fig. 7). These findings suggest that miR-511 targets SOX9 to inactivate the PI3K/Akt pathway in breast cancer cells.

miR-511 hinders breast cancer tumor growth in vivo. A xenograft tumor experiment was performed to assess whether miR-511 contributes to the tumorigenesis of breast cancer cells in vivo. MDA-MB-231 cells were transfected with miR-511 mimics or miR-NC and were subcutaneously administered into the hind flanks of nude mice. In order to meet ethical requirements, all the nude mice were sacrificed before the tumor xenografts reached $2 \mathrm{~cm}$. The maximum tumor burden was $1.8 \mathrm{~cm}$. Consistent with the in vitro results, miR-511-overexpressing xenografts exhibited a lower tumor volume $(\mathrm{P}<0.05$; Fig. $8 \mathrm{~A}$ and $\mathrm{B})$ and tumor weight $(\mathrm{P}<0.05$; Fig. $8 \mathrm{C})$ compared with miR-NC expressing tumors. In addition, the data obtained by RT-qPCR analysis revealed that miR-511 was specifically upregulated in the xenografts of the miR-511 mimics-overexpressing group compared the miR-NC-transfected group ( $\mathrm{P}<0.05$; Fig. 8D). Western blot analysis demonstrated that the xenografts of the miR-511-overexpressing group expressed lower levels of SOX9, p-PI3K, and p-Akt than the xenografts of the miR-NC-transfected group (Fig. 8E). Together, these results suggest that miR-511 targets SOX9 to inhibit breast cancer tumor growth in vivo via deactivation of the PI3K/Akt pathway.

\section{Discussion}

Numerous studies have revealed that an miRNA subset is aberrantly expressed in nearly all human cancer types, including breast cancer (32-34). The dysregulation of miRNAs is involved in the tumorigenesis and progression of breast cancer due to their negative regulation of downstream target genes (35-37). It is generally accepted that miRNAs may have tumor-suppressive or oncogenic roles in breast cancer and participate in the regulation of numerous cellular biological processes $(16,38,39)$. Notably, development of effective computational models for the prediction of potential breast cancer-associated miRNAs has been a research hot spot in recent years (40-45). Therefore, the identification of deregulated miRNAs in breast cancer may provide important insights into the diagnosis and treatment of patients with this disease. miR-511 has been identified as an important gene expression regulator in breast cancer (21). In this study, it was aimed to measure miR-511 expression in breast cancer, analyze the clinical characteristics of miR-511 in breast cancer, examine the detailed roles of miR-511 in breast cancer progression and determine the underlying mechanisms. To the best of knowledge, this is the first report to demonstrate that miR-511 is downregulated in breast cancer and that it inhibits malignant behaviors by directly targeting SOX9 and regulating the $\mathrm{PI} 3 \mathrm{~K} / \mathrm{Akt}$ pathway.

To elucidate the clinical value of miR-511, RT-qPCR was performed to detect expression in breast cancer tissues and cell lines. It was observed that miR-511 was significantly downregulated in breast cancer tissues and cell lines, and the downregulation of miR-511 was associated with lymph node metastasis and tumor stage. This finding is in agreement with previous studies (17-19) on the expression pattern of miR-511 in several human cancer subtypes. For example, the expression level of miR-511 was lower in colorectal cancer tissues and cell lines than in adjacent non-neoplastic tissues and normal human colon epithelium cell lines, respectively (17). miR-511 expression was also reported to be decreased in gastric cancer (18), and lung adenocarcinoma (19). By contrast, miR-511 was upregulated in hepatocellular carcinoma (20). These inconsistent findings indicate that the expression status of miR-511 exhibits tissue specificity. Thus, this miRNA could potentially be a biomarker for the diagnosis of patients with specific cancer subtypes. 
A

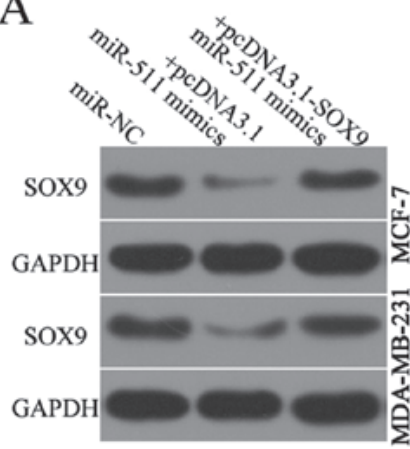

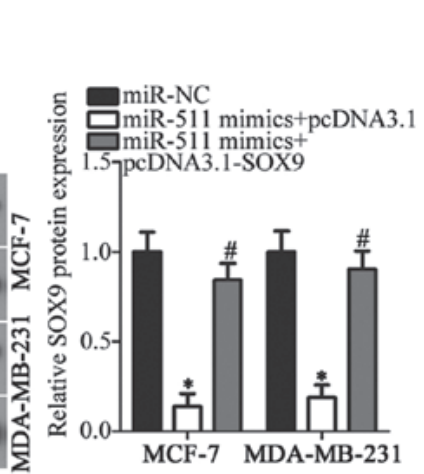

B
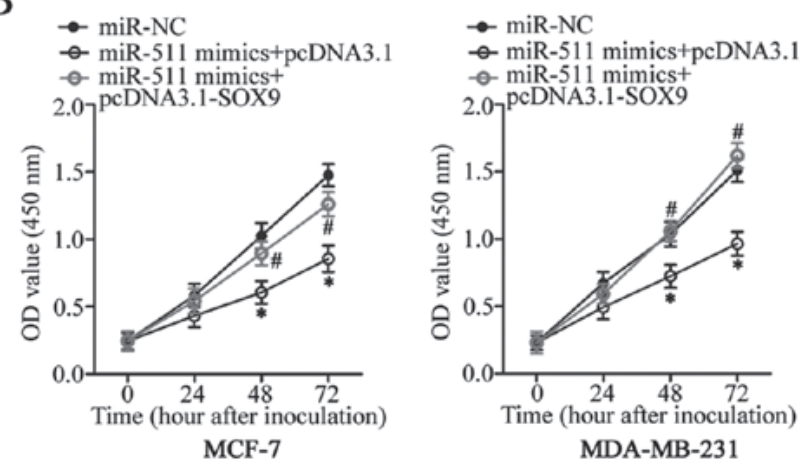

C

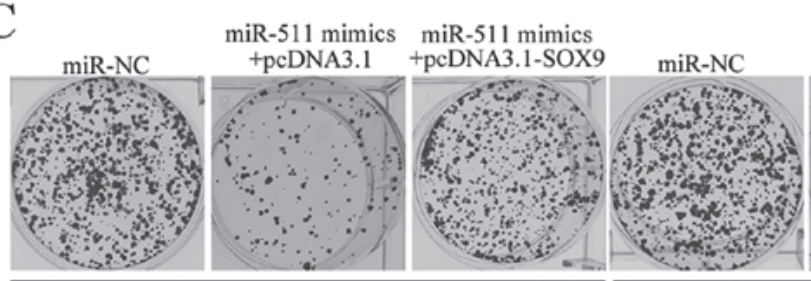

MCF-7

D

MCF-7

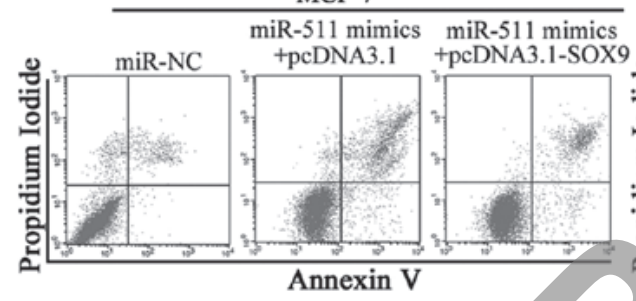

E

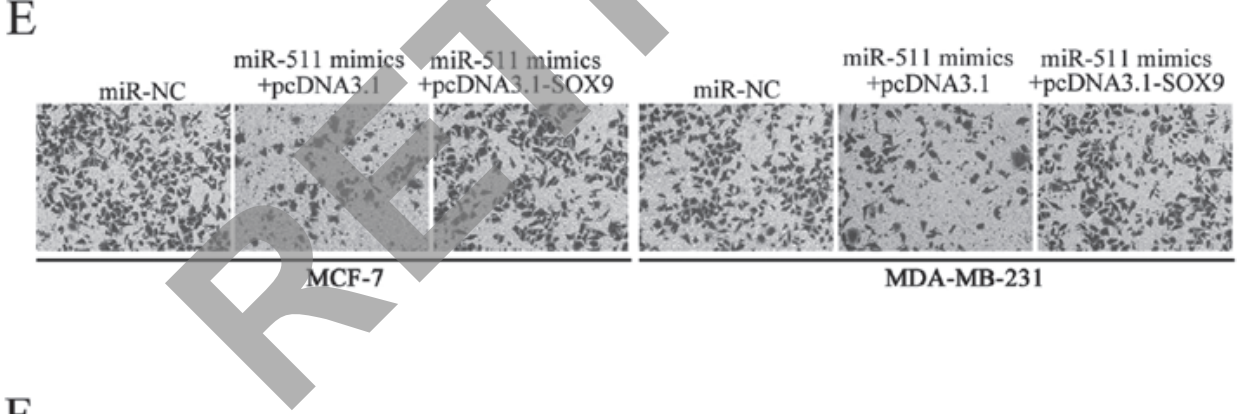

F

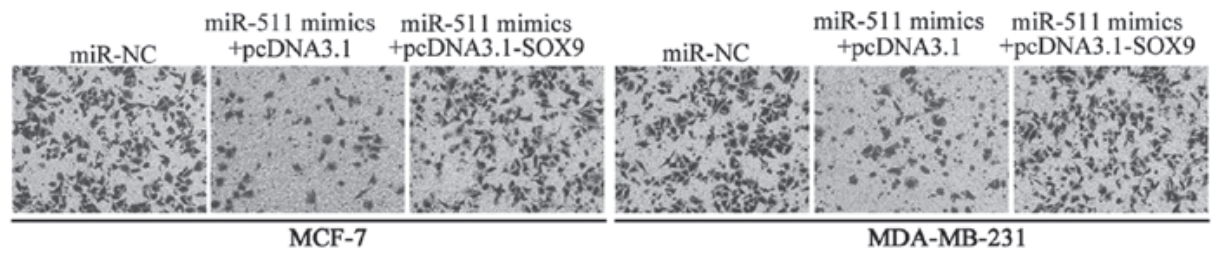

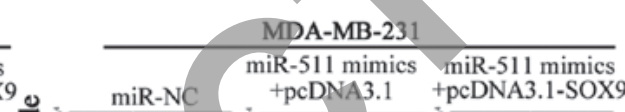

MDA-MB-231

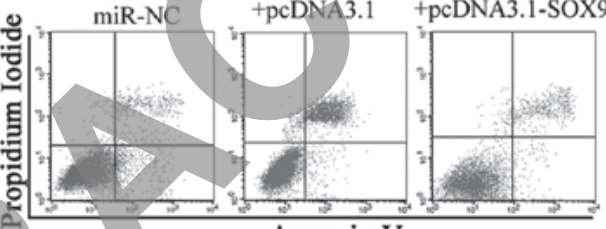

Annexin V

miR-511 mimics
+pcDNA3-511 mimics
+pcDNA3.1-SOX9
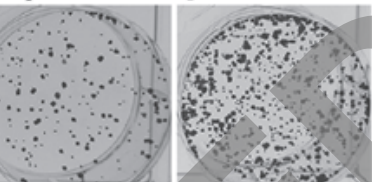

MDA-MB:231

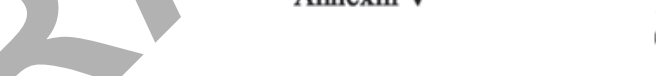
miR-NC $\operatorname{miR}-511$ mimics+pcDNA3.1 $\square$ miR-511 mimics+
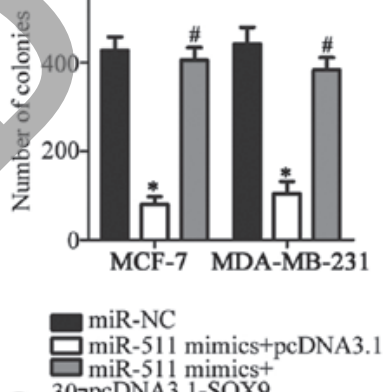

307pcDNA3.1-SOX9
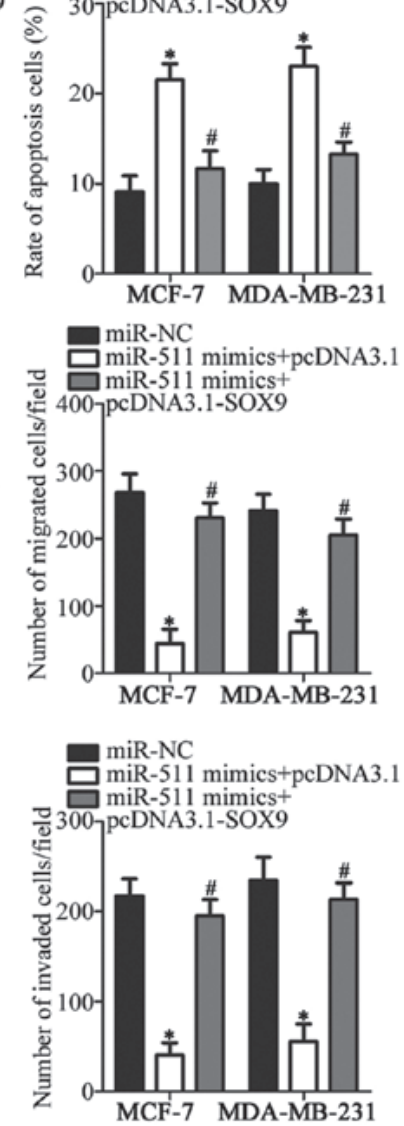

Figure 6. SOX9 mediates the miR-511-induced suppression of breast cancer progression. MCF-7 and MDA-MB-231 cells were co-transfected with miR-511 mimics and pcDNA3.1-SOX9 or pcDNA3.1. (A) Western blot analysis was conducted at $72 \mathrm{~h}$ post-transfection to detect SOX9 protein expression. (B) CCK-8 and (C) colony formation assays were applied to evaluate the proliferation and colony formation of the indicated cells. (D) Apoptosis rate in the cell lines described above was analyzed using flow cytometry. (E) Migration and (F) invasion of the cell lines described above were determined by migration and invasion assays. ${ }^{*} \mathrm{P}<0.05$ vs. miR-NC; ${ }^{\text {P }}<0.05$ vs. miR-511 mimics + pcDNA3.1. miR, microRNA; NC, negative control; SOX, SRY-box 9; OD, optical density.

The data from functional assays further demonstrated that miR-511 upregulation inhibits breast cancer cell proliferation and colony formation, promotes apoptosis, impedes cell migration and invasion and decreases in vivo tumor growth. 

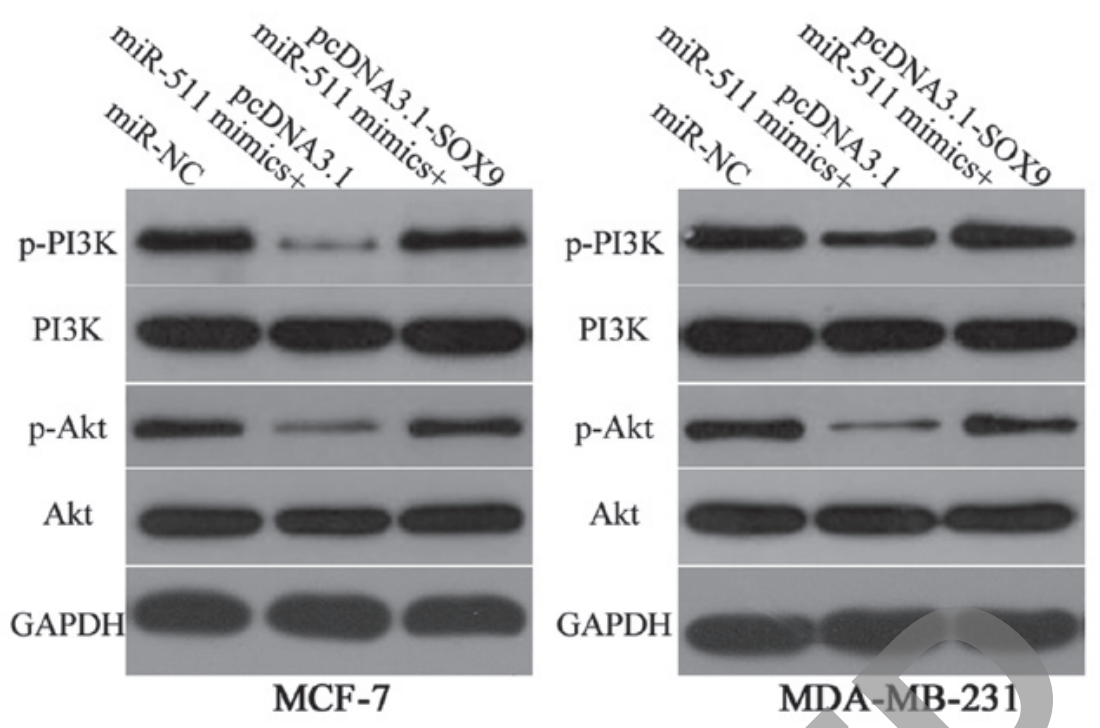

Figure 7. miR-511 deactivates the PI3K/Akt signaling pathway in breast cancer cells by targeting SOX9. miR-511 mimics, along with pcDNA3.1-SOX9 or pcDNA3.1, were co-transfected into MCF-7 and MDA-MB-231 cells. At $72 \mathrm{~h}$ post-transfection, western blot analysis was performed to measure the abundance of several proteins associated with the PI3K/Akt pathway. miR, microRNA; NC, negative control; SOX, SRY-box 9; p-, phospho-; PI3K, phosphoinositide 3-kinase; Akt, Akt serine/threonine kinase.

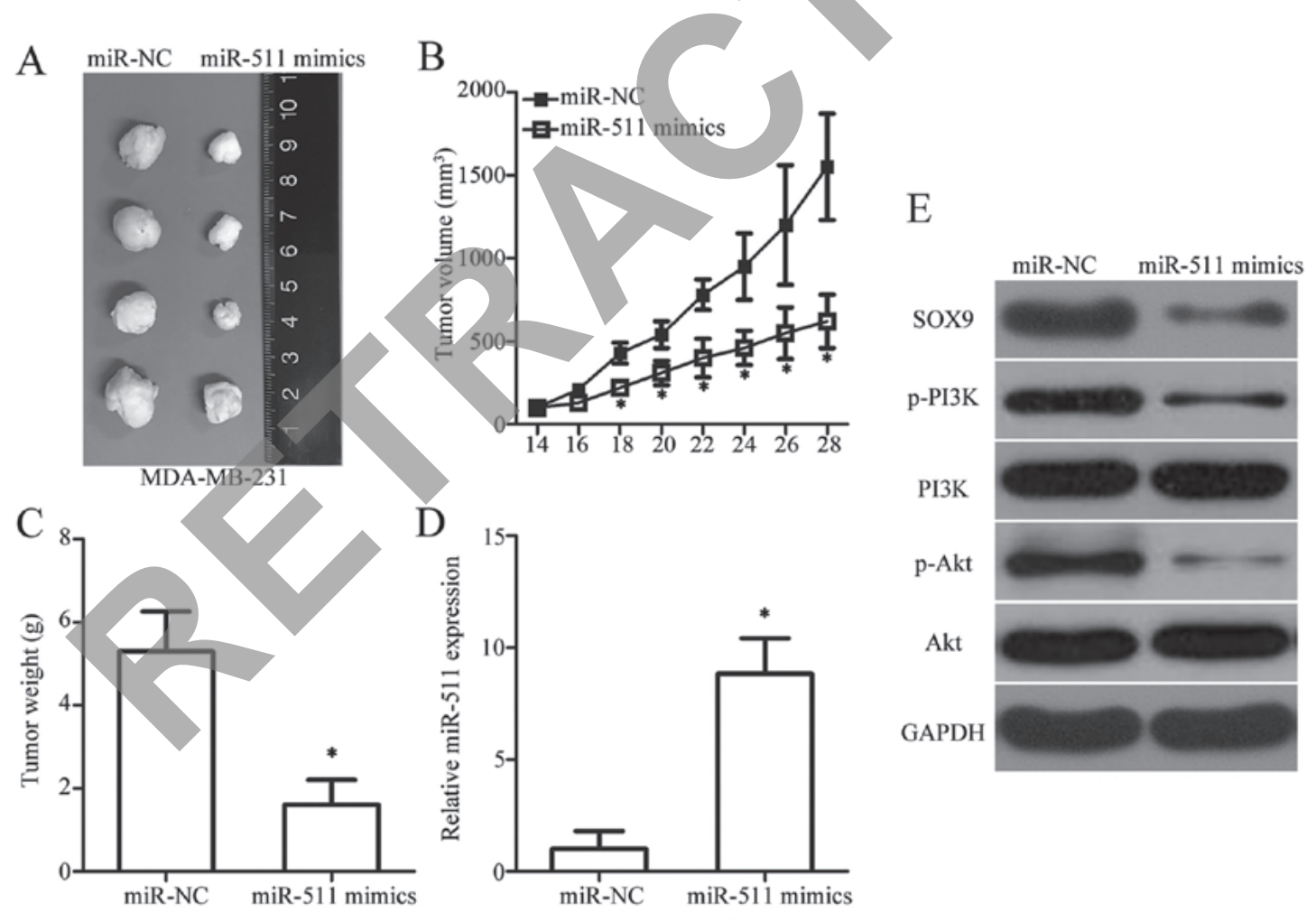

Figure 8. miR-511 upregulation inhibits breast cancer tumor growth in vivo. A xenograft tumor model was established by subcutaneously injecting BALB/C nude mice with MDA-MB-231 cells transfected with miR-511 mimics or miR-NC. (A) Representative images of the miR-511 mimics-transfected and miR-NC-transfected isolated xenograft tumors. (B) Tumor width and length were measured every 4 days for 4 weeks. miR-511-overexpressing xenografts exhibited a lower tumor volume than the miR-NC-transfected xenografts. (C) Nude mice were sacrificed 4 weeks after tumor implantation and the tumor xenografts were excised and weighed. (D) Reverse transcription-quantitative polymerase chain reaction analysis of miR-511 expression in the xenografts of the miR-511 mimics-overexpressing and miR-NC-transfected groups. " $\mathrm{P}<0.05$ vs. miR-NC. (E) Western blot analysis was performed to detect the abundance of SOX9 protein and several proteins associated with the PI3K/Akt pathway in the xenografts of the miR-511 mimics-overexpressing and miR-NC-transfected groups. miR, microRNA; NC, negative control; SOX, SRY-box 9; p-, phospho-; PI3K, phosphoinositide 3-kinase; Akt, Akt serine/threonine kinase.

Aberrant expression of miR-511 has previously been reported to have a role in multiple types of human cancer. For instance, miR-511 overexpression prohibited the proliferative and invasive abilities of colorectal cancer cells in vitro (17).
In gastric cancer, the restoration of miR-511 expression suppressed cell growth and induced cell cycle arrest (18). miR-511 was also validated as a tumor suppressor affecting cell proliferation, apoptosis, cell cycle and radioresistance 
in lung adenocarcinoma $(19,46)$. However, miR-511 was identified as an oncogene in hepatocellular carcinoma (20). These conflicting findings imply that the functional roles of miR-511 in malignancy have tissue specificity, suggesting that miR-511 may be developed as a valuable therapeutic target for treating patients with these specific cancer types.

Previous studies have validated multiple target genes of miR-511, including heparin binding growth factor (17) in colorectal cancer, tripartite motif containing 24 in gastric cancer (18), tribbles pseudokinase 2 (19) and BCL2 associated $\mathrm{X}$ apoptosis regulator (46) in lung adenocarcinoma, and BTG anti-proliferation factor 1 in hepatocellular carcinoma (20). Validation of the direct targets of miR-511 is important for understanding its roles in the development of breast cancer and may assist the development of effective therapeutic techniques. Thus, the molecular mechanisms underlying the tumor-suppressive activity of miR-511 in breast cancer were examined. SOX9, a member of the sex-determining region Y box family, was demonstrated to be a direct target of miR-511 in breast cancer. SOX9 has been reported to be upregulated in a number of human cancers, including prostate cancer (47), non-small cell lung cancer (48) and colorectal cancer (49). SOX9 was also highly expressed in breast cancer and reported to be significantly associated with estrogen receptor expression and tumor grade (22). Breast cancer patients with high expression of SOX9 exhibited shorter overall survival than those with low expression $(22,23)$. Numerous other studies have supported the importance of SOX9 in breast cancer occurrence and development through the regulation of multiple biological behaviors (24-28). In the current study, it was demonstrated that miR-511 targets SOX9 to inhibit the malignant progression of breast cancer via the PI3K/ Akt pathway. Thus, SOX9 knockdown using miR-511-based targeted therapy may be a potential therapeutic strategy for patients with breast cancer in the future.

In summary, the current study demonstrated that miR-511 was downregulated in breast cancer tissues and cell lines. Functional experiments revealed that miR-511 overexpression inhibited the malignant progression of breast cancer in vitro and in vivo. Mechanistically, SOX9 was identified as a direct target of miR-511 in breast cancer cells. The present study provides novel insights into the mechanisms underlying breast cancer genesis and progression, and highlights a potential therapeutic target for breast cancer. However, rescue experiments were not performed to explore whether SOX 9 expression can rescue the in vivo tumor growth inhibition induced by miR-511. In addition, a PI3K inhibitor was not used to illustrate whether the SOX9-induced rescue of miR-511 growth and metastasis inhibition could be blocked. Furthermore, the effect of miR-511 on the ERK pathway in breast cancer was not investigated. These are limitations of the study and these limitations will be resolved in the near future.

\section{Acknowledgements}

Not applicable.

\section{Funding}

Not applicable.

\section{Availability of data and materials}

The datasets used and/or analyzed during the present study are available from the corresponding author on reasonable request.

\section{Authors' contributions}

YZ designed this research. WP and NY performed RT-qPCR, western blot analysis, CCK-8 assay, colony formation assay, flow cytometry analysis, and migration and invasion assays. LH and LW performed xenograft tumor experiment and luciferase reporter assay. All authors have read and approved the final manuscript.

\section{Ethics approval and consent to participate}

The present study was approved by the Research Ethics Committee of the Fourth Affiliated Hospital of Harbin Medical University, and was performed in accordance with the Declaration of Helsinki and the guidelines of the Ethics Committee of the Fourth Affiliated Hospital of Harbin Medical University. Written informed consent was obtained from all patients for the use of their clinical tissues.

\section{Patient consent for publication \\ Not applicable.}

\section{Competing interests}

The authors declare that they have no competing interests.

\section{References}

1. DeSantis CE, Ma J, Goding Sauer A, Newman LA and Jemal A: Breast cancer statistics, 2017, racial disparity in mortality by state. CA Cancer J Clin 67: 439-448, 2017.

2. Ferlay J, Soerjomataram I, Dikshit R, Eser S, Mathers C, Rebelo M, Parkin DM, Forman D and Bray F: Cancer incidence and mortality worldwide: Sources, methods and major patterns in GLOBOCAN 2012. Int J Cancer 136: E359-E386, 2015.

3. Veronesi U, Boyle P, Goldhirsch A, Orecchia R and Viale G: Breast cancer. Lancet 365: 1727-1741, 2005.

4. Nakamura S, Yagata $H$, Ohno S, Yamaguchi H, Iwata H, Tsunoda N, Ito Y, Tokudome N, Toi M, Kuroi K, et al: Multicenter study evaluating circulating tumor cells as a surrogate for response to treatment and overall survival in metastatic breast cancer. Breast Cancer 17: 199-204, 2010.

5. Cancer Genome Atlas Network: Comprehensive molecular portraits of human breast tumours. Nature 490: 61-70, 2012.

6. Weigelt B, Peterse JL and van 't Veer LJ: Breast cancer metastasis: Markers and models. Nat Rev Cancer 5: 591-602, 2005.

7. Cardoso F, Costa A, Senkus E, Aapro M, André F, Barrios CH, Bergh J, Bhattacharyya G, Biganzoli L, Cardoso MJ, et al: 3rd ESO-ESMO International Consensus Guidelines for Advanced Breast Cancer (ABC 3). Ann Oncol 28: 16-33, 2017.

8. Friedman RC, Farh KK, Burge CB and Bartel DP: Most mammalian mRNAs are conserved targets of microRNAs. Genome Res 19: 92-105, 2009.

9. Bartel DP: MicroRNAs: Genomics, biogenesis, mechanism, and function. Cell 116: 281-297, 2004.

10. Ma XP, Zhang T, Peng B, Yu L and Jiang K: Association between microRNA polymorphisms and cancer risk based on the findings of 66 case-control studies. PLoS One 8: e79584, 2013.

11. Singh T and Adams BD: The regulatory role of miRNAs on VDR in breast cancer. Transcription 8: 232-241, 2017.

12. Lü L, Mao X, Shi P, He B, Xu K, Zhang S and Wang J: MicroRNAs in the prognosis of triple-negative breast cancer: A systematic review and meta-analysis. Medicine (Baltimore) 96: e7085, 2017. 
13. Evans-Knowell A, LaRue AC and Findlay VJ: MicroRNAs and Their Impact on Breast Cancer, the Tumor Microenvironment, and Disparities. Adv Cancer Res 133: 51-76, 2017.

14. Cao MQ, You AB, Zhu XD, Zhang W, Zhang YY, Zhang SZ, Zhang KW, Cai H, Shi WK, Li XL, et al: miR-182-5p promotes hepatocellular carcinoma progression by repressing FOXO3a. J Hematol Oncol 11: 12, 2018.

15. Hu TB, Chen HS, Cao MQ, Guo FD, Cheng XY, Han ZB and Li MQ: MicroRNA-421 inhibits caspase-10 expression and promotes breast cancer progression. Neoplasma 65: 49-54, 2018

16. Lv ZD, Yang DX, Liu XP, Jin LY, Wang XG, Yang ZC, Liu D, Zhao JJ, Kong B, Li FN, et al: MiR-212-5p Suppresses the epithelial-mesenchymal transition in triple-negative breast cancer by targeting Prrx2. Cell Physiol Biochem 44: 1785-1795, 2017.

17. He S, Wang G, Ni J, Zhuang J, Zhuang S, Wang G, Ye Y and Xia W: MicroRNA-511 inhibits cellular proliferation and invasion in colorectal cancer by directly targeting hepatoma-derived growth factor. Oncol Res, 2018 Oncol Res: Jan 10, 2018 (Epub ahead of print). doi: 10.3727/096504018X15154094331876.

18. Fang Z, Zhang L, Liao Q, Wang Y, Yu F, Feng M, Xiang X and Xiong J: Regulation of TRIM24 by miR-511 modulates cell proliferation in gastric cancer. J Exp Clin Cancer Res 36: 17, 2017.

19. Zhang C, Chi YL, Wang PY, Wang YQ, Zhang YX, Deng J, Lv CJ and Xie SY: miR-511 and miR-1297 inhibit human lung adenocarcinoma cell proliferation by targeting oncogene TRIB2. PLoS One 7: e46090, 2012

20. Zhang SQ, Yang Z, Cai XL, Zhao M, Sun MM, Li J, Feng GX, Feng JY, Ye LH, Niu JQ, et al: miR-511 promotes the proliferation of human hepatoma cells by targeting the 3'UTR of B cell translocation gene 1 (BTG1) mRNA. Acta Pharmacol Sin 38: $1161-1170,2017$

21. de Anda-Jáuregui G, Espinal-Enríquez J, Drago-García D and Hernández-Lemus E: Nonredundant, highly connected MicroRNAs control functionality in breast cancer networks. Int J Genomics 2018: 9585383, 2018.

22. Chakravarty G, Moroz K, Makridakis NM, Lloyd SA, Galvez SE Canavello PR, Lacey MR, Agrawal K and Mondal D: Prognostic significance of cytoplasmic SOX9 in invasive ductal carcinoma and metastatic breast cancer. Exp Biol Med (Maywood) 236: $145-155,2011$

23. Riemenschnitter C, Teleki I, Tischler V, Guo W and Varga Z: Stability and prognostic value of Slug, Sox 9 and Sox 10 expression in breast cancers treated with neoadjuvant chemotherapy. Springerplus 2: 695, 2013.

24. Müller P, Crofts JD, Newman BS, Bridgewater LC, Lin CY, Gustafsson JA and Ström A: SOX9 mediates the retinoic acidinduced HES-1 gene expression in human breast cancer cells Breast Cancer Res Treat 120: 317-326, 2010.

25. Chakravarty G, Rider B and Mondal D: Cytoplasmic compartmentalization of SOX 9 abrogates the growth arrest response of breast cancer cells that can be rescued by trichostatin A treatment. Cancer Biol Ther 11: 71-83, 2011.

26. Wang H, He L, Ma F, Regan MM, Balk SP, Richardson AL and Yuan X: SOX9 regulates low density lipoprotein receptorrelated protein 6 (LRP6) and T-cell factor 4 (TCF4) expression and Wnt/ $\beta$-catenin activation in breast cancer. J Biol Chem 288 6478-6487, 2013.

27. Fazilaty H, Gardaneh M, Akbari P, Zekri A and Behnam B: SLUG and SOX9 cooperatively regulate tumor initiating niche factors in breast cancer. Cancer Microenviron 9: 71-74, 2016.

28. Jeselsohn R, Cornwell M, Pun M, Buchwalter G, Nguyen M, Bango C, Huang Y, Kuang Y, Paweletz C, Fu X, et al: Embryonic transcription factor SOX9 drives breast cancer endocrine resistance. Proc Natl Acad Sci USA 114: E4482-E4491, 2017

29. Livak KJ and Schmittgen TD: Analysis of relative gene expression data using real-time quantitative PCR and the 2(-Delta Delta C(T)) method. Methods 25: 402-408, 2001.

30. Liu Z, Yan Y, Cao S and Chen Y: Long non-coding RNA SNHG14 contributes to gastric cancer development through targeting miR-145/SOX9 axis. J Cell Biochem 119: 6905-6913, 2018.
31. Xia S, Feng Z, Qi X, Yin Y, Jin J, Wu Y, Wu H, Feng Y and Tao M: Clinical implication of Sox9 and activated Akt expression in pancreatic ductal adenocarcinoma. Med Oncol 32: 358, 2015.

32. Drusco A and Croce CM: MicroRNAs and cancer: A long story for short RNAs. Adv Cancer Res 135: 1-24, 2017.

33. Kanwal R, Plaga AR, Liu X, Shukla GC and Gupta S MicroRNAs in prostate cancer: Functional role as biomarkers. Cancer Lett 407: 9-20, 2017.

34. O'Bryan S, Dong S, Mathis JM and Alahari SK: The roles of oncogenic miRNAs and their therapeutic importance in breast cancer. Eur J Cancer 72: 1-11, 2017.

35. Zheng Q, Cui X, Zhang D, Yang Y, Yan X, Liu M, Niang B, Aziz F, Liu S, Yan Q, et al: miR-200b inhibits proliferation and metastasis of breast cancer by targeting fucosyltransferase IV and $\alpha 1,3$-fucosylated glycans. Oncogenesis 6: e358, 2017.

36. Maimaitiming A, Wusiman A, Aimudula A, Tudahong $\mathrm{T}$ and Aisimutula D: WITHDRAWN: Downregulation of MicroRNA-152 and Inhibition of Cell Proliferation, Migration, and Invasion in Breast Cancer. Oncol Res, Oncol Res: Jun 15 2017 (Epub ahead of print). doi: 10.3727/096504017X14974821 032421 .

37. Wang J, Song C, Tang H, Zhang C, Tang J, Li X, Chen B and Xie X: miR-629-3p may serve as a novel biomarker and potential therapeutic target for lung metastases of triple-negative breast cancer. Breast Cancer Res 19: 72, 2017.

38. Sui Y, Zhang X, Yang H, Wei W and Wang M: MicroRNA-133a acts as a tumour suppressor in breast cancer through targeting LASP1. Oncol Rep 39: 473-482, 2018.

39. Degli Esposti D, Aushev VN, Lee E, Cros MP, Zhu J, Herceg Z, Chen J and Hernandez-Vargas H: miR-500a-5p regulates oxidative stress response genes in breast cancer and predicts cancer survival. Sci Rep 7: 15966, 2017

40. Chen X, Wang L, Qu J, Guan NN and Li JQ: Predicting miRNA-disease association based on inductive matrix completion. Bioinformatics: Jun 22, 2018 (Epub ahead of print). doi: 10.1093/ bioinformatics/bty503.

41. Chen X, Xie D, Wang L, Zhao Q, You ZH and Liu H: BNPMDA: Bipartite Network Projection for MiRNA-disease association prediction. Bioinformatics 34: 3178-3186, 2018.

42. Chen X and Huang L: LRSSLMDA: Laplacian regularized sparse subspace learning for MiRNA-disease association prediction. PLOS Comput Biol 13: e1005912, 2017.

43. You ZH, Huang ZA, Zhu Z, Yan GY, Li ZW, Wen Z and Chen X: PBMDA: A novel and effective path-based computational model for miRNA-disease association prediction. PLOS Comput Biol 13: e1005455, 2017.

44. Chen X, Xie D, Zhao Q and You ZH: MicroRNAs and complex diseases: From experimental results to computational models. Brief Bioinform: Oct 17, 2017 (Epub ahead of print). doi: 10.1093/bib/ bbx130.

45. Chen X, Huang L, Xie D and Zhao Q: EGBMMDA: Extreme gradient boosting machine for MiRNA-disease association prediction. Cell Death Dis 9: 3, 2018.

46. Zhang HH, Pang M, Dong W, Xin JX, Li YJ, Zhang ZC, Yu L, Wang PY, Li BS and Xie SY: miR-511 induces the apoptosis of radioresistant lung adenocarcinoma cells by triggering BAX. Oncol Rep 31: 1473-1479, 2014.

47. Wang H, Leav I, Ibaragi S, Wegner M, Hu GF, Lu ML, Balk SP and Yuan X: SOX9 is expressed in human fetal prostate epithelium and enhances prostate cancer invasion. Cancer Res 68: 1625-1630, 2008.

48. Zhou CH, Ye LP, Ye SX, Li Y, Zhang XY, Xu XY and Gong LY: Clinical significance of SOX9 in human non-small cell lung cancer progression and overall patient survival. J Exp Clin Cancer Res 31: 18, 2012

49. Bruun J, Kolberg M, Nesland JM, Svindland A, Nesbakken A and Lothe RA: Prognostic significance of $\beta$-catenin, E-cadherin, and SOX9 in colorectal cancer: Results from a large populationrepresentative series. Front Oncol 4: 118, 2014. 